\title{
668
}

\section{Aëorolith, gefallen am 17. Juli 1840, 20 Lieues westlich von Mailand.}

\begin{abstract}
$A$
in 17. Juli $7 \frac{1}{2}$ Uhr Morgens hörten die Astronomen auf der Sternwarte Brera eineu donnerähnlichen Kuall, wclchen sie dem Fall cines Meteorsteines zuschrieben. Nach Aussage der Bewohner von den Dörfern Locate und Golnsecca, in der l'mgegend von Mailand, sab man zur sclben Zeit drei weilslich leuchtende Meteore in der Juft, zwci kleine und cin selir grofse's, die vnu Ost nacb West gingen: und bold darauf hürle man einen Kuall wie einen Kanonensclues, - Aul dem (iebiet von Ceresello, Provinz Casal-Monlferrat, westlich von Moiland, 211 Lieues von Locate fiel cin Metrorstein, 10 l'fund 2,2 Unz. Picmontesar Qewicht schwer ( 12 Uuz. $=1$ Picmonteser Pfund), der über 20 Zull tief in dic Erde cilldrang. Zwei andere Stcine tielın iu der Nähe, wurden aber uichl aufyefunden. (Compt, reml. $T . X I \dot{p} .213$. )
\end{abstract}

berichligungeuzum Aufsalz vou ll. Abich.

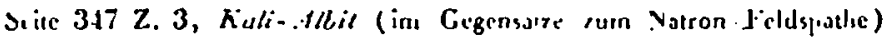
stall h.2li

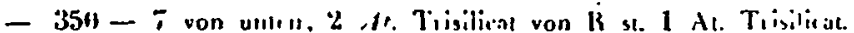

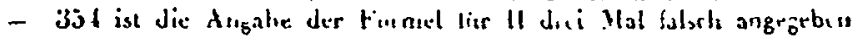

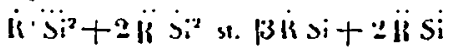

- 357 Z. 7. 4 stt. I risilical st. 3 .1t. Tricilicat

- 358 Z. 2:, Aali-slbit st. Kali und thit 